Investigations

\title{
Selection of Inbred Lines of Alfalfa for Creating Synthetic Varieties
}

\author{
Nuraliyev Serikbay Kenzhebaevich, Meirman Galiolla Tolendinovich, Abayev Serik Saribaevich, \\ Bulatova Kulpash Mansurovna and Yerzhebayeva Raushan Saylauvna \\ LLC "The Kazakh Scientific Research Institute of Agriculture and Plant Breeding", \\ 040909, Almaty Region, Karasai District, Settl. Almalybak, St. Erlepesova, 1, Kazakhstan
}

\author{
Article history \\ Received: 08-09-2017 \\ Revised: $12-09-2017$ \\ Accepted: 23-12-2017 \\ Corresponding Author: \\ Nuraliyev Serikbay \\ Kenzhebaevich \\ LLC "The Kazakh Scientific \\ Research Institute of \\ Agriculture and Plant \\ Breeding", 040909, Almaty \\ Region, Karasai District, Settl. \\ Almalybak, St. Erlepesova, 1, \\ Kazakhstan \\ E-mail: nuraliyev-s@yandex.ru
}

\section{Introduction}

Among the cultivated range of fodder crops in the conditions of South and South-East of Kazakhstan, alfalfa on the arable lands is considered to be the best by productivity and fodder quality. In the irrigated arable land, varieties of creeping alfalfa are mostly cultivated.

Strategic goals of the research include creating the high-yield, most adapted varieties of alfalfa of synthetic type based on the use of inbred lines. Of the total, rather long schemes of selection, creating inbred lines is allocated into a separate phase of research. Selected inbred lines will be used as initial (parent) forms in breeding of multicomponent synthetic varieties (Meyrman, 1986; Meirman, 1991a). The efficiency of using combinatory-valuable inbred lines in breeding has been proven by the practical results in creating highyielding synthetic varieties of alfalfa that are approved for use and protected by patents:
- Variety Kokorai that consists of 4 lines and one heterozygous genotype - $\mathrm{J}_{3}-53$ from population Semirechenskaya, $\mathrm{J}_{2}-212$ from $\mathrm{K}-41340$ (Italy), $\mathrm{J}_{2} \mathrm{a}-132$ from $\mathrm{K}-6940$ (India), $\mathrm{J}_{2}-101$ from variety Kapchagayskaya 80 and from heterozygous plant $23-4$ from variety Omskaya 8893

- Variety Osimtal - 5 inbred lines - D - 19/24, D 8/65 from variety Dawson (USA), C - 21/14 from variety Semirechenskaya local (Kazakhstan),K 8/41 from variety Kapchagaiskaya 80, (Kazakhstan) I - 7/3 from variety Iolotanskaya (Turkmenistan)

- Variety Kokbalausa - from 7 inbred lines - K 14/27 from variety Kapchagayskaya 80 and C - 6/33 from variety Semirechenskaya local (Kazakhstan), D - 17/09 from variety Dawson (USA), I 17/54, I 20/12 from variety Iolotanskaya (Turkmenistan), P 12/02, I - 14/08 from variety Payton (France) 


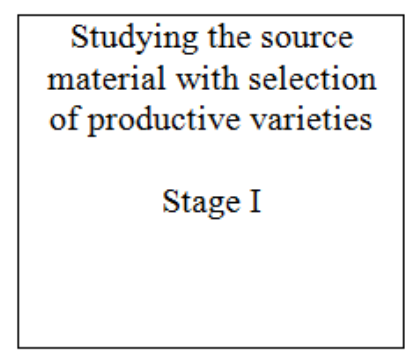

Evaluation and
selection of lines with
high general combining
ability
Stage IV

Creating inbred lines with the use
of the self-fertility trait with
defining inbreeding lines in
generations of $\mathrm{J}_{2}$ and $\mathrm{J}_{3}$
Stage II

Laying isolated polycrossing plots with synthesis of new varieties based on selected lines and breeding them to generations Syn 2 and Syn 3

Stage V

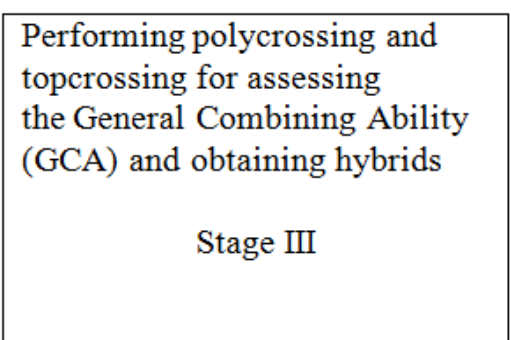

Assessing reference and experimental strain tests in nurseries with selection of the most productive varieties, and sending them to the State strain test. Stage VI

Fig. 1: Procedure of the selection process with the use of inbred lines

From the genetic (scientific) point of view, selection of inbred lines and their separation for synthesis of highyielding varieties are the most effective ways for achieving the ultimate goal, i.e. the results (products) will be successfully used in creating new varieties. Field evaluation and assessment of the general combining ability were used in selection of inbred lines; we will be the first to perform research for identifying the level of homozygosity of the lines with the use of a molecular marker and by the micropropagation of breedingvaluable lines, ensuring their genetic homogeneity. The inbred lines included into the composition of new varieties will be protected by patents, same as subsequently the varieties based on these lines.

The success of the breeding with the use of inbred lines is due to the large scale of research of selffertility and creating inbred lines on this basis $\left(\mathrm{J}_{3}\right)$, as well as of assessing the general combining ability for determining the prospects of using them as initial components of synthetic varieties (Meirman, 1991b; 1991c; Portablia et al., 1982). The overall progress of the breeding process is schematically shown in Fig. 1, where the stages of breeding program implementation with the use of inbred lines are conventionally shown. This paper will discuss the results of research in stages II to IV.

The research is aimed at creating inbred lines in generations $\mathrm{J}_{2}-\mathrm{J}_{3}$, based on studying the self-fertility trait for selection of alfalfa inbred varieties. Efficiency of bringing the level of inbred generations to the $J_{2}-J_{3}$ has been proven by the studies of Meirman (1991c).

\section{Materials and Methods of the Studies}

Self-fertility of the varietal population with the aim of obtaining line $\mathrm{J}_{1}$ was studied for Lucerne on 250 genotypes in the composition of 10 varieties: $\mathrm{K}-36049$ (Kazakhstan), K - 4382 (Georgia), K - 44568 (Russia), $\mathrm{K}$ - 6231 (Russia), K - 46249 (USA), 6014 (Malaysia), $\mathrm{K}-47705$ (USA), K - 28460 (Ukraine), K - 33481 (Finland), K - 45081 (Georgia).

To study self-fertility for creating inbred lines, at least 30 flowers were isolated with gauze insulators in the studied objects. After 2-3 days, the insulators were removed and immature flowers of the truss in various different phases of budding were carefully removed with tweezers. Flowers ready for pollination were counted (by Vozny, stage IV) and mechanically opened with the help of a dissecting needle, causing their artificial selfpollination. In the subsequent procedures systematic observation was performed with counting of beans with seeds for determining the level of self-fertility. The level of self-fertility was determined in percent for each genotype separately by the ratio of artificially opened flowers and the flowers of set beans from the seed. The total of over 10.5 thousand flowers of alfalfa was self-pollinated.

Seeds from self-pollination were an object for continued process of bringing inbred lines to generations $\mathrm{J}_{2}$ and $\mathrm{J}_{3}$.

The objects of study for assessing the genetic diversity and degree of homozygosity were varieties of alfalfa Kokorai, Kokbalausa and Osimtal and their components -inbred lines I3: Kokorai (I2-132, I2-101; I3-53; I2 -212), Kokbalausa (R-14/27; S-6/33, D-17/09; 
I-17/54; I-20/12; P-12/02; P-14/08), Osimtal (D-19/24; D-8/65; S-21/04; R-8/41; I-7/3).

For detecting DNA samples, seeds of the studied varieties of alfalfa were sown in a greenhouse and primers were chosen for the most polymorphic DNA markers of the SSR type.

Primers for the analysis of the microsatellite DNA were chosen according to the literature data (Amanov, 2012; Cholastova and Knotova, 2012).

For extracting the DNA, approximately $200 \mathrm{mg}$ of the tissue of the second real leaf were taken into a $2 \mathrm{~mL}$ Eppendorf tube, $800 \mu \mathrm{L}$ of STAB extracting buffer containing $1.0 \%$ PVP40, $0.2 \%$ BME in addition to the basic components were added and homogenized with a pestle. The extracted and precipitated DNA was redissolved in $1 \mathrm{M}$ of $\mathrm{NaCl}$ and treated with RNase A (10 $\mathrm{mg} / \mathrm{mL}$ ), then precipitated with chilled $100 \%$ ethanol and washed with $70 \%$ ethanol. The extracted DNA was dissolved in ddH2O, the quality and concentration was measured on spectrophotometer Jenway, then the concentration was brought up to $0.1 \mu \mathrm{g} / \mu \mathrm{L}$.

For the PCR analysis, the composition of the reaction mixture was the following: 20ng of genomic DNA, $1.6 \mathrm{x}$ PCR buffer, $2.5 \mathrm{mM}$ of $\mathrm{MgCI} 2,210 \mathrm{nM}$ of each dNTP, 7-10pmole of each primer, 0.5 units of Taq polymerase. Amplification was performed on thermocycler iCycler "BIORAD". The conditions for amplification were: Initial denaturation $-94^{\circ} \mathrm{C}$ for 5 min, followed by seven $30 \mathrm{sec}$ cycles at $94^{\circ} \mathrm{C}, 30 \mathrm{sec}$ at $63^{\circ} \mathrm{C}$ and $45 \mathrm{sec}$ at $72^{\circ} \mathrm{C}$. The annealing temperature was decreased by $1^{\circ} \mathrm{C}$ at each cycle. This was followed by 30 cycles: $30 \mathrm{sec}$ at $94^{\circ} \mathrm{C}, 30 \mathrm{sec}$ at $57^{\circ} \mathrm{C}$ and $45 \mathrm{sec}$ at $72^{\circ} \mathrm{C}$, with the final elongation of $10 \mathrm{~min}$. Electrophoresis of the amplification products was performed in polyacrylamide gel $(8 \%$ acrylamide, $1 \times$ $\mathrm{TBE})$ at $200 \mathrm{~V}$ for $70 \mathrm{~min}$. The products of amplification were stained with ethidium bromide. The obtained electrophoregram was documented with the use of the QuantumST4 gel documenting system. The dimensions of the products were determined using computer program "quantumcapt, imageanalysis" in relation to the markers of the DNA fragment length.

Seeds from open pollination of inbred lines for assessing the general combining ability were obtained from polycrossnurseries. When collecting seeds, homonymous numbers were combined from all 10 replications of the polycross for the maximum uniformity of the genetic contribution of each line into the newly obtained hybrid population.

Selection assessment based on the commercially valuable characteristics and selection of alfalfa lines by the general combining ability were performed at breeding nurseries consisting of 1,240 numbers. Based on the availability of the seeding material, the nurseries were laid in one-row way with the length of the plots 1 to 4 meters and the inter-row spacing of $30 \mathrm{~cm}$.

After every 10 numbers (lines), standard grade Semirechenskaya local was sown. For assessment of the line, the yield of the green mass mowed was taken into account by means of direct weighing of the entire weight from the plot. The yields of the green mass were compared to those of the standard variety.

The materials for micropropagation were 2 inbred lines of alfalfa - S 21/14 and K13/07.

Alfalfa explants were articulations: Healthy, young and rapidly growing shoots were cut out from the plants grown in the greenhouse. The shoots are freed from leaves, petioles and stipules and cut $2 \mathrm{~mm}$ under and above each articulation, in order to obtain $5 \mathrm{~mm}$ long cuttings with one bud. 100 explants were sown in each line.

Alfalfa explants were sterilized with a $20 \%$ solution of sodium hypochlorite with a drop of Twin- 80 for $8-10$ min and then rinsed in sterile distilled water.

As a medium for the first and second stage micropropagation, the standard nutrient medium Murashige and Skoog (1962).

was used, which contained $2 \mathrm{mg} / \mathrm{l}$ of 6benzylaminopurine, $0.5 \mathrm{mg} / \mathrm{L}$ of indole acetic acid, $30 \mathrm{~g} / \mathrm{L}$ of sucrose, $6 \mathrm{~g} / \mathrm{L}$ of agar, $2.5 \mathrm{mg} / \mathrm{L}$ of ascorbic acid.

The medium for rooting was the White medium with the addition of $15 \mathrm{~g} / \mathrm{L}$ sucrose, $2 \mathrm{mg} / \mathrm{L}$ of IAA and $6 \mathrm{~g} / \mathrm{L}$ if agar.

\section{Results}

In the process of alfalfa evolution, many mechanisms have been developed that prevent selfpollination, including:

- The presence of the protective mucus layer (membrane) on the surface of the pistil stigma that prevents germination of own pollen in a closed flower

- The inclusion of the reproductive elements in the carina so that the pollen may fall on the stigma only when the flower is opened by pollinators

- The presence of the glue-like excretion and thick lint on the central part of the vexillum that pollen or small insects (thrips) with pollen stick to, which also promotes cross-pollination in case of auto-tripping

- More intensive germination of alien pollen grains than own pollen on the pistil tissues

- Genetically determined self-incompatibility

These limitations determine the benefit of crosspollination, supporting the heterozygous basis of the population.

In breeding, studying of alfalfa self-fertility by the method of self-pollination by artificial opening the 
flowers is adopted, which allows to determine the potential tendency to self-fertilization. Self-fertility is expressed by indicators such as the number of beans with seeds, the number of seeds per one bean or flower and they provide similar information about self-fertility.

Alfalfa is a plant that is cross-pollinated by specialized insects. However, it has been found that many plants in the varieties of the population can form seeds in the conditions of self-pollination, although generally the genetic mechanisms prevail that endure advantages of cross-pollination. The main of them are more active growth and development of the pollen tube and fertilization in case of cross-pollination. This is confirmed by the fact that artificial crossing without testectomy of alfalfa flowers has always ensured hybridity of the seed, while self-fertilization occurs fairly rarely. In this regard, the method of crossing alfalfa without removing pollen beforehand is widely used.

A genetic mechanism that would explain manifestation of self-incompatibility of alfalfa determined by $\mathrm{Sf}$ - mutations in locus Shas been proposed. In accordance with it, self-incompatibility of tetraploid alfalfa is manifested only if the mutant Sf - allele is found in no less than two loci. It is the first time that self-fertile forms of alfalfa with different flowers morphology with symptoms of flowers selfopening and cleistogamous pollination have been induced under the action of chemical mutagens. In self-incompatible plants, the tip of the vexillum is round; in mutants with self-opening flowers, there is a notch on the top part of the vexillum; in the cleistogamous form, it is pointed.

Analysis of the level of self-fertility in the original genotypes by individual genotypes (20-31 plants) showed the possibility of using them for selection of inbred lines. The average level of self-fertility in the population varied between 18.6 and $48.2 \%$, i.e., in the population, self-fertile plants are found more frequently than self-incompatible ones (Table 1).
In the nature, fertility in case of free pollination overlaps self-fertility, since manifestations of the latter are limited by the structure of the flower and the entomophilous nature of pollination. Automatic opening of alfalfa flowers (autotripping) that contributes to the manifestation of self-fertility in the nature is also limited, being a reserve factor of evolution.

In the studied populations of alfalfa varieties, its constituent genotypes are very diverse by the way of breeding - from self-incompatible to rather highly selffertile form. Most genotypes of the population can be generally used to generate inbred lines and perform selections at the level of the line with the aim of improving the general combining ability. In our experiments, changes in the self-fertility level reached $68 \%$, the lower limits being 3 to $12 \%$; only separate genotypes (13\%) showed self-incompatibility.

By the results of the self-fertility level analysis of the studied populations of alfalfa varieties and by the set of other indicators, elite plants have been selected with SF level higher than $50 \%$. The total of 50 genotypes have been selected, including, variety K-36049 - 8 genotypes, K-6231 - 8, K-6014 - 4, K-47705 - 12, K-28460 - 4, K$33481-6, \mathrm{~K}-45081-8$ genotypes to be used to continue the process of inbreeding up to level $\mathrm{J}_{2}$ and $\mathrm{J}_{3}$ as potential parent lines for assessing their general combining ability.

Using a similar method, inbreeding of genotypes was performed on the selected lines of alfalfa $\mathrm{J}_{2}$ for transferring them into older generations of inbreeding, respectively, of alfalfa $J_{3}$. During the field test on 100 lines $J_{2}$ by phenotype, 33 lines were selected for inbreeding for translating the line into $\mathrm{J}_{3}$. Next, 313 genotypes were subjected to inbreeding by isolating their flowers and determining their SF level. Next, based on the SF indicator exceeding 40\%, 100 lines were selected at the level of individual genotypes for assessing their general combining ability in the process of consecutive stages of breeding (Table 2).

Table 1: Level of Self-Fertility (SF) in heterogeneous varieties of alfalfa and selection of initial genotypes for further laying inbred lines

\begin{tabular}{|c|c|c|c|c|}
\hline Initial variety & $\begin{array}{l}\text { The number of } \\
\text { genotypes subjected to } \\
\text { self-pollination }\end{array}$ & $\begin{array}{l}\text { The average SF } \\
\text { level in the } \\
\text { population, \% }\end{array}$ & $\begin{array}{l}\text { Limits of } \\
\text { variability, from } \\
\text { and to\% }\end{array}$ & $\begin{array}{l}\text { Elite genotypes with SF } \\
\text { level above } 50 \text { (pcs.) } \\
\text { have been selected } \\
\text {--------------------- } \\
\text { quantity }\end{array}$ \\
\hline K-36049 & 31 & $43.6 \pm 4.0$ & $0-64$ & 8 \\
\hline K-4382 & 24 & $19.4 \pm 3.3$ & $0-33$ & - \\
\hline K-44568 & 22 & $23.1 \pm 2.4$ & $3-44$ & - \\
\hline K-6231 & 20 & $28.6 \pm 2.8$ & $5-64$ & 8 \\
\hline K-46249 & 28 & $30.1 \pm 3.0$ & $8-38$ & - \\
\hline K-6014 & 25 & $48.2 \pm 3.5$ & $7-53$ & 4 \\
\hline $\mathrm{K}-47705$ & 31 & $26.3 \pm 1.5$ & $7-60$ & 12 \\
\hline $\mathrm{K}-28460$ & 25 & $38.6 \pm 3.6$ & $0-53$ & 4 \\
\hline K-33481 & 24 & $40.3 \pm 3.8$ & $0-58$ & 6 \\
\hline $\mathrm{K}-45081$ & 20 & $18.6 \pm 1.1$ & $12-68$ & 8 \\
\hline Total & 250 & - & - & 50 \\
\hline
\end{tabular}


Table 2: Results of alfalfa inbreeding on $\mathrm{J}_{2}$ for transferring into generation $\mathrm{J}_{3}$

\begin{tabular}{|c|c|c|c|c|c|c|}
\hline $\begin{array}{l}\text { Initial } \\
\text { line } \mathrm{J}_{2}\end{array}$ & $\begin{array}{l}\text { The number } \\
\text { of studied } \\
\text { lines }\end{array}$ & $\begin{array}{l}\text { Selected by } \\
\text { the phenotype } \\
\text { for laying line } \mathrm{J}_{3}\end{array}$ & $\begin{array}{l}\text { Genotypes } \\
\text { subjected to self- } \\
\text { pollination }\end{array}$ & $\begin{array}{l}\text { Average } \\
\text { SF,\% }\end{array}$ & $\begin{array}{l}\text { Limits of } \\
\text { variation from } \\
\text { and to } \%\end{array}$ & $\begin{array}{l}\text { Elite genotypes (lines) } \\
\text { Were selected with SF } \\
\text { level above } 40 \% \text { for } \\
\text { assessing the general } \\
\text { combining ability }\end{array}$ \\
\hline S-15-3 & 10 & 3 & 35 & $38.3 \pm 3.1$ & $24-43$ & 7 \\
\hline S-17-18 & 12 & 3 & 40 & $41.2 \pm 3.3$ & $30-43$ & 18 \\
\hline $\mathrm{K}-14-3$ & 7 & 2 & 38 & $50.4 \pm 4.0$ & $41-54$ & 10 \\
\hline $52-26$ & 8 & 4 & 40 & $46.8 \pm 3.5$ & $40-49$ & 10 \\
\hline $54-36$ & 8 & 2 & 25 & $31.9 \pm 2.4$ & $27-43$ & 8 \\
\hline $41-11$ & 6 & 1 & 10 & $52.0 \pm 5.0$ & $50-54$ & 15 \\
\hline $41-14$ & 16 & 5 & 50 & $40.0 \pm 3.6$ & $38-43$ & 6 \\
\hline $68-73$ & 13 & 6 & 37 & $39.6 \pm 2.9$ & $30-44$ & 16 \\
\hline $87-71$ & 9 & 4 & 20 & $51.3 \pm 3.8$ & $50-54$ & 2 \\
\hline $59-91$ & 11 & 3 & 18 & $50.4 \pm 4.1$ & $48-51$ & 8 \\
\hline Total & 100 & 33 & 313 & - & - & 100 \\
\hline
\end{tabular}

Table 3: Varieties of alfalfa populations and inbred lines that constitute the variety

\begin{tabular}{lll}
\hline Variety name & Structure & Genetic diversity \\
\hline Kokorai & I2 $-132 ; \mathrm{I} 2-101 ; \mathrm{I} 3-53 ; \mathrm{I} 2-212$ & 0.33 \\
Kokbalausa & $\mathrm{K}-14 / 27 ; \mathrm{S}-6 / 33, \mathrm{D}-17 / 09 ; \mathrm{I}-17 / 54 ; \mathrm{I}-20 / 12 ; \mathrm{P}-12 / 02 ; \mathrm{P}-14 / 08$ & 0.29 \\
Osimtal & $\mathrm{D}-19 / 24 ; \mathrm{D}-8 / 65 ; \mathrm{S}-21 / 04 ; \mathrm{K}-8 / 41 ; \mathrm{I}-7 / 3$ & 0.36 \\
\hline
\end{tabular}

The genetic diversity of 3 varietal populations of Lucerne and the degree of homozygosity of inbred lines that constitute the population by the spectra of spare proteins in the seeds was assessed (Table 3).

The genetic diversity of the varieties ranged between 0.29 and 0.36 and was the highest in the Osimtal variety.

Analysis of the spare proteins spectra in the seeds of the studied varieties and their initial inbred components showed that the genomes of various varieties and their components, inbred lines, were partly similar. Similar results at the DNA level marking were obtained by the research of Russian scientists (Smolenskaya et al., 2008). Absolute homozygosity is not achieved even in highly inbred lines. Figure 2-4 show spectra of population varieties "Kokorai" and "Kokbalausa" and "Osimtal" and their inbred lines.

To characterize the geoplasma of alfalfa varieties and their components, we used four SSR markers, the characteristics of which are shown in Table 4.

The dimensions of the obtained allelic variants in our study were somewhat different from the results obtained by other authors, which is due to the difference between the studied objects.

Figures 5 and 6 show the allele variant of locus AFCA 11 and alleles of locus B21E13 of the "Osimtal" population variety and its components, 5 inbred lines.

The results of the study showed that genomes of different varieties and inbred lines were partially similar, both in the spectra of reserve proteins of seeds and in the amplified DNA fragments of the type of SSR markers.

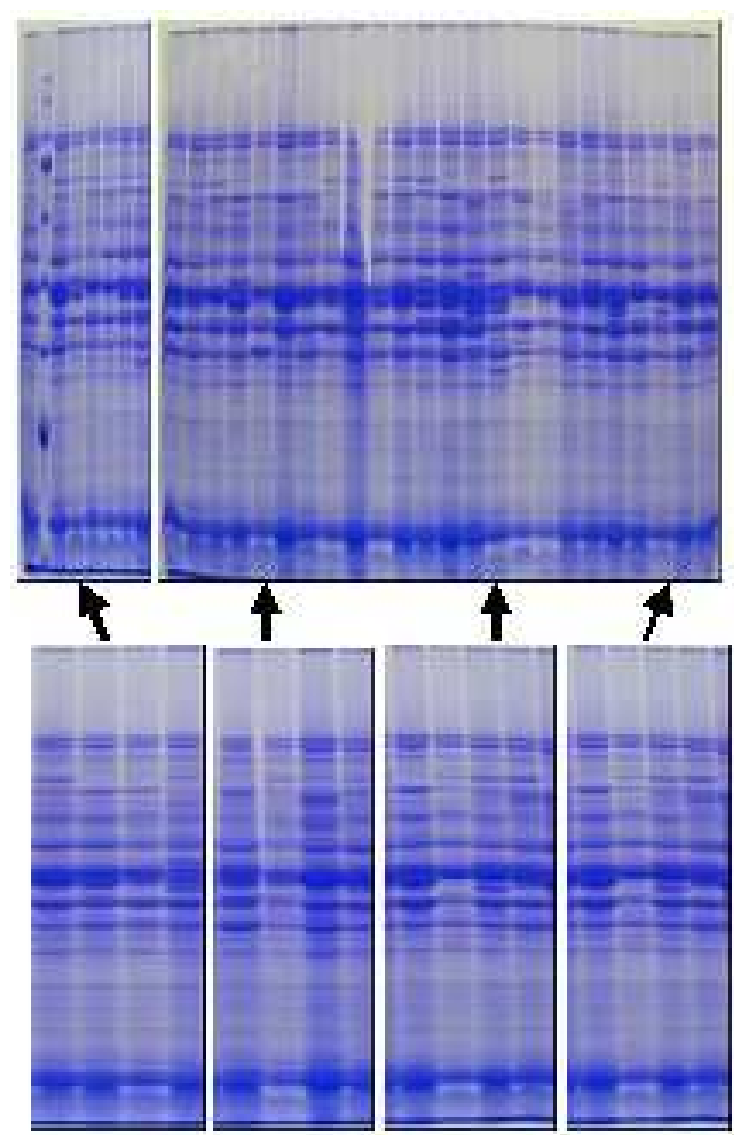

(a)

(b)

(c)

(d)

Fig. 2: Spectra of reserve proteins in the Kokorai variety of alfalfa and its component inbred lines (a) 12-132 (b) 12-101 (c) 13-53 (d) 12-212 


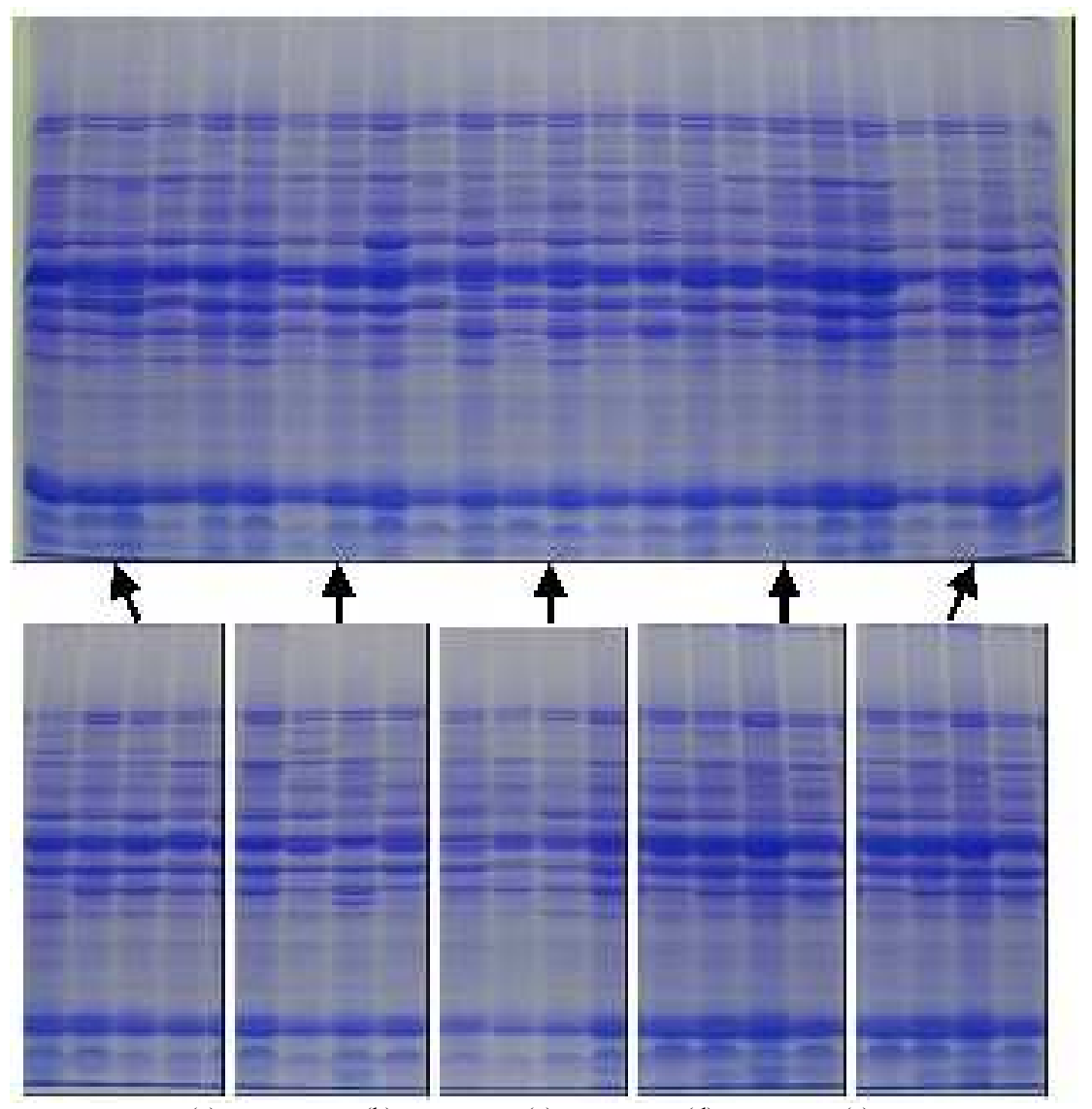

(a)

(b)

(c)

(d)

(e)

Fig. 3: Spectra of reserve proteins in the Osimtal variety of alfalfa and its component inbred lines (a) D-19/24 (b) D-8/65 (c) S$21 / 04$ (d) K-8/41 (e) I-7/3
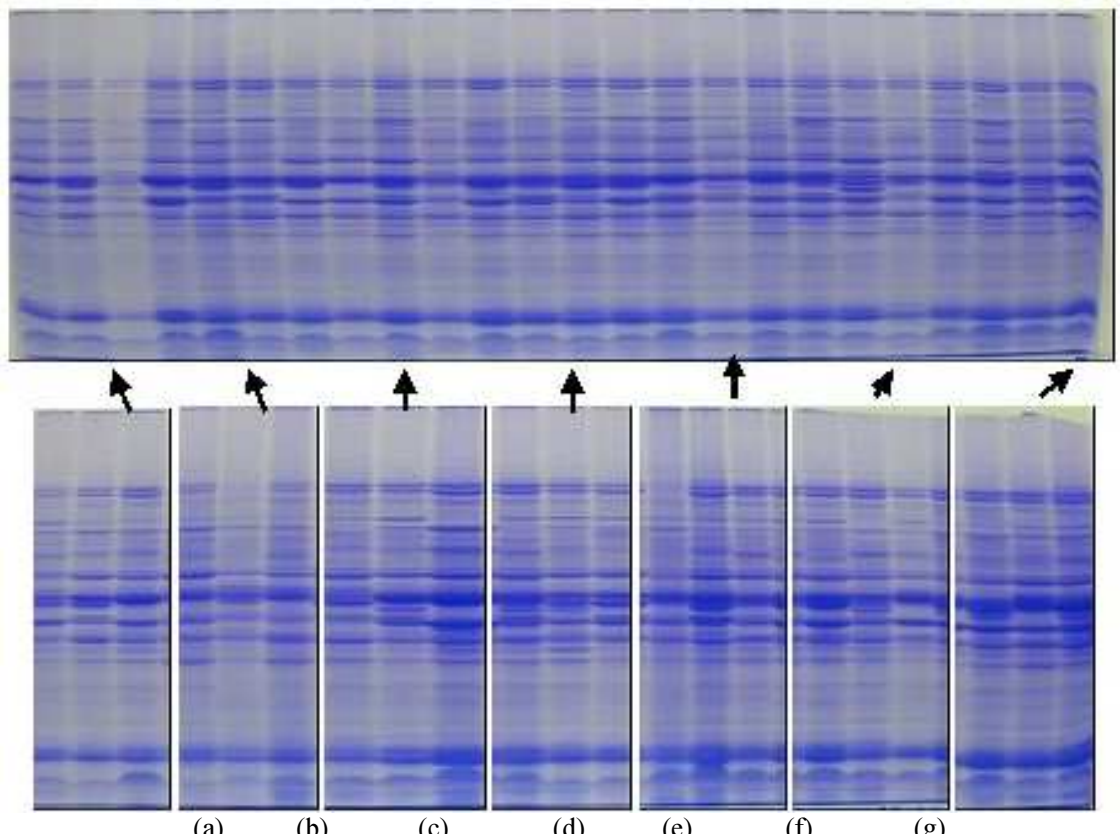

(a) (b)

(c)

(d)

(e)

(f)

(g)

Fig. 4: Spectra of reserve proteins in the Kokbalausa variety of alfalfa and its component inbred lines (a) K-14/27 (c) S-6/33 (c) D$17 / 09$ (d) I-17/54 (e) I-20/12 (f) P-12/02 (g) P14/08 


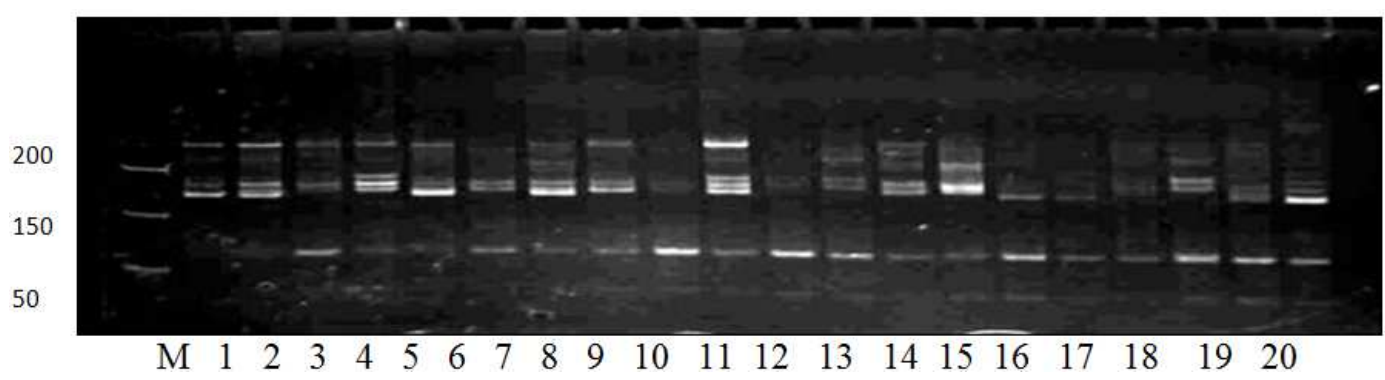

Fig. 5: Diversity of the alleles of locus AFCA 11 of the Osimtal population variety and its components Note: 1, 2-variety Osimtal, 35: Individual plants of the variety; 6-8: D-19/24; 9-11 D-8/65; 12-14: S-21/14; 15-17: L-8/41; 18-20: I-7/3

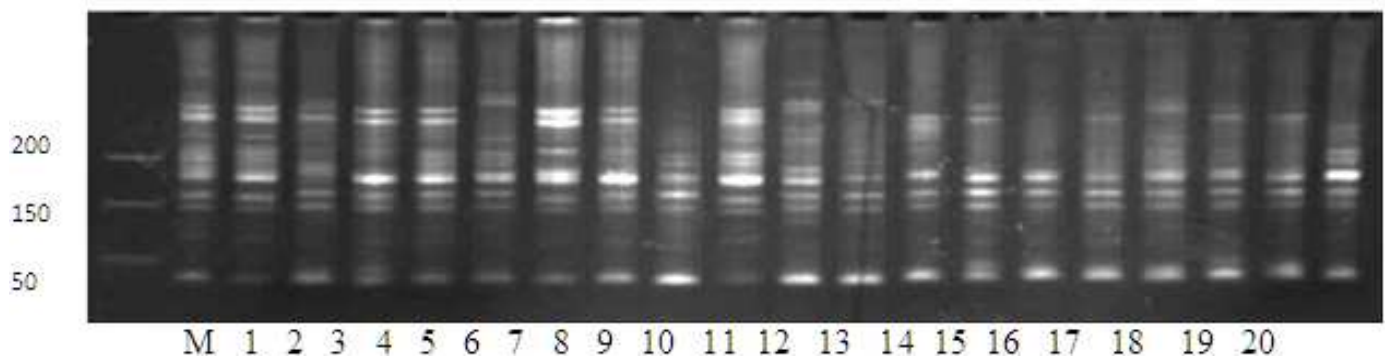

Fig. 6: Diversity of the alleles of locus B21E13 of the Osimtal population variety and its components Note: 1, 2-variety Osimtal, 35: Individual plants of the variety; 6-8: D-19/24; 9-11 D-8/65; 12-14: S-21/14; 15-17: L-8/41; 18-20: I-7/3

Table 4: SSR primers used in for assessing the polymorphism of alfalfa varieties and their component inbred lines

\begin{tabular}{llll}
\hline Locus & Direct and reverse primers & Alleles dimensions, bps (sources) & The results of our study, bps \\
\hline AFCA 11 & $\begin{array}{l}\text { (f) CTTGAGGGAACTATTGTTGAGT } \\
\text { (r) AACGTTTCCCAAAACATACTT }\end{array}$ & $136-160 *$ & $128-202$ \\
B21E13 & $\begin{array}{l}\text { (f) GCCGATGGTACTAATGTAGG } \\
\text { (r) AAATCTTGCTTGCTTCTCAG }\end{array}$ & - & $146-256$ \\
AAC-008 & $\begin{array}{l}\text { (f) ACTCTTAGGAGCAGGATCAC } \\
\text { (r) GCAGGAGCTCTAGTGGTATG }\end{array}$ & $231 * *$ & $167-245$ \\
FMT 13 & $\begin{array}{l}\text { (f) GATGAGAAAATGAAAAGAAC } \\
\text { (r) CAAAAACTCACTCTAACCAC }\end{array}$ & $162-204 * * *$ \\
& & $141-163$ \\
\hline Note: $*$ Diwan et al. $(1997 ;$ He et al., 2009; Flajoulot et al., 2005)
\end{tabular}

Inbred lines allow relatively high heterozygosity; reaching homozygosity at the level of molecular markers is a long process that is not required for practical breeding.

The best lines were subjected to micropropagation.

Slicing of the donor plants from 2 inbred lines of alfalfa (S-21/14 and K13/07) for the purpose of selecting explants (axillary buds) for micropropagation and further planting was performed on 24.04.2016. 100 explants of each line were introduced into the in vitro culture.

On the 10-15 day of cultivation, formation of new shoots from axillary buds (3-6 units) was noted (Fig. 7). $12 \%$ (24 PCs) explants were rejected due to infection. In $9 \%$ of tubes, inhibition of the primary explant growth was observed, due to excretion of toxic substances into the nutrient medium.

The results of micropropagation of 2 inbred lines of alfalfa lines 21/14 and K13/07 are shown in Table 5.
After 30 days of cultivation, the number of the formed shoots per 1 explant was counted. The plants were characterized by a good degree of development and leaves' color. Line S-21/14 showed the average development of $5.5 \pm 2.3$ mericlones with the length of $22.4 \pm 2.6 \mathrm{~mm}$, line $\mathrm{K} 13 / 07-6.4 \pm 2.1$ mericlones with the length of $20.4 \pm 2.2 \mathrm{~mm}$. The reproduction factor on the average was 5.7 .

The results of alfalfa micropropagation itself, 3,200 microclones of 2 inbred alfalfa lines (S-21/14 and K13/07) were obtained. All developed axillary buds were transplanted to the new nutrient medium without hormones for growth and development. The percentage of infection was $16 \%$. Tubes with explants were cultivated in a photoculture installation with the 16/8-h photoperiod at light intensity of 10-15 thousand luxes. After formation of 3 to 4 leaves, well-developed microclones $(2,500$ pieces $)$ were transplanted for rooting 
into the White medium. Assessment of the rooting process showed that root formation was observed in 1,100 microclones (44\%) (Fig. 8).

All rooted 1,100 alfalfa plants were planted in specially prepared soil (soil-and-peat mixture and vermiculite - 1:1). Of the 1,100 plants, 900 plants adapted to the soil, which made $82 \%$.

Thus, the coefficient of micropropagation of alfalfa plants from inbred lines averaged to 5.3. The percentage of rooting of theobtained microclones was within $44 \%$.

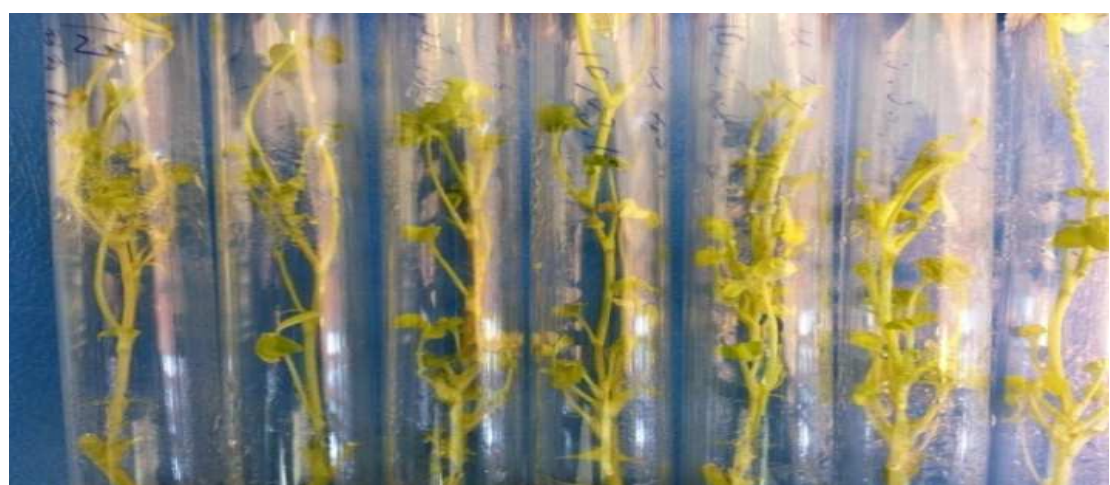

(a)

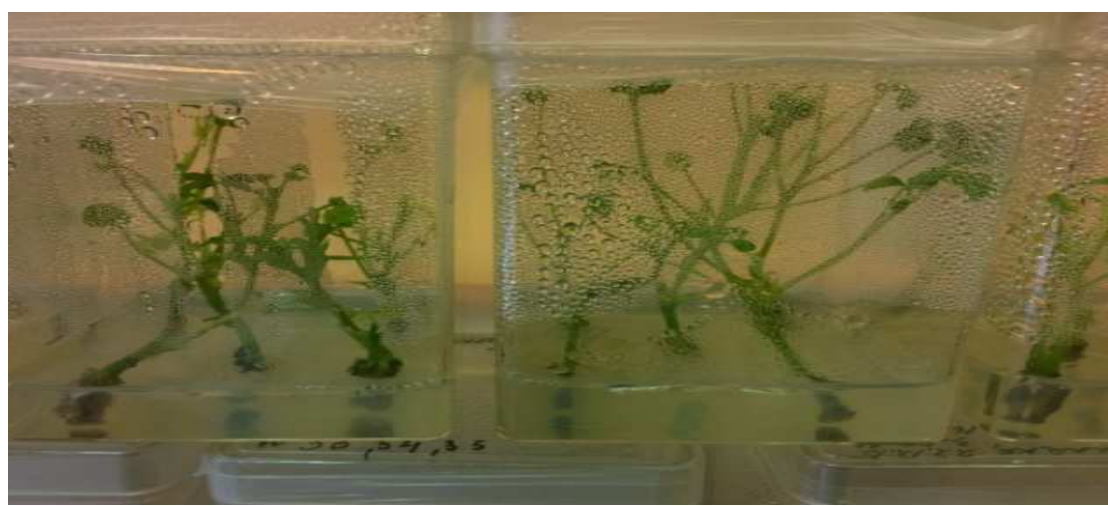

(b)

Fig. 7: Growth and development of explants of inbred alfalfa lines (a) in test tubes, (b) in Magenta boxes

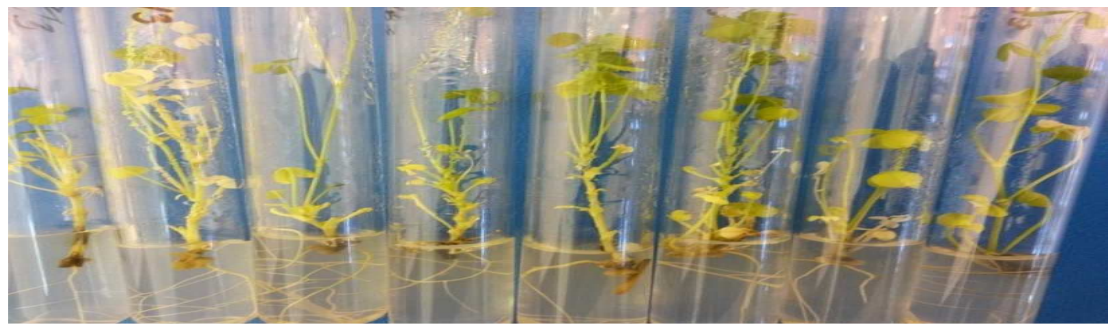

Fig. 8: Rooted alfalfa microclones

Table 5: Results 2 micropropagation of two inbred alfalfa lines

\begin{tabular}{llll}
\hline Line name & $\begin{array}{l}\text { The number of planted } \\
\text { explants, pieces }\end{array}$ & $\begin{array}{l}\text { The number of formed } \\
\text { axillary shoots per explants }\end{array}$ & $\begin{array}{l}\text { The length of } \\
\text { axillary shoots, mm }\end{array}$ \\
\hline 1 passage & & & $22.4 \pm 2.6$ \\
S-21/14 & 100 & $5.4 \pm 2.3$ & $20.4 \pm 2.2$ \\
K13/07 & 100 & $6.1 \pm 2.1$ & $19.5 \pm 2.3$ \\
2 passage & & & $18.5 \pm 2.0$ \\
S-21/14 & 350 & $5.6 \pm 2.1$ & \\
K13/07 & 410 & $5.1 \pm 1.8$ & \\
\hline
\end{tabular}




\section{Discussion}

In the populations of alfalfa, wide variability of plants is observed by the degree of fertility: From complete self-incompatibility to self-fertility. With that, alfalfa populations are dominated by plants that are, in varying degrees, capable of self-fertilization, while fully self-sterile plants amount to only $20.0 \%$.

Thus, the artificial self-pollination can be used to differentiate alfalfa populations based on self-fertility, which is very important in terms of obtaining inbred lines and increasing the seed productivity in the conditions of insufficient number of pollinating insects.

Polymorphism of the plants in terms of reproduction and combination of cross-pollination with selfpollination is one of the most important advantages of alfalfa population, which creates the possibility combining outcrossing and inbreeding. Self-fertility that ensures the possibility of inbreeding is useful for eliminating unwanted genes and increasing uniformity of the offspring in terms of the beneficial characteristics, while high level of self-incompatibility, bringing up the advantage of autocrossing, helps maintaining high viability of the population.

In recent years, the issue of alfalfa self-fertility has been paid more and more attention to. First, it is related to the necessity of creating inbred lines for breeding synthetic varieties created on the basis of a combination of self-pollination and cross-pollination, which provides a biological advantage of the hetero - and homozygous balance of the population. Second, methods of using self-fertility and of using such an attribute that would be required of its manifestation, autotripping in the breeding for increasing seed yield are widely developed. The first alfalfa varieties with high seed productivity have already been created and released based on self-fertility and ease of flower opening.

Self-fertility is an important trait, through which the process of inbreeding - homozygotization of the source material as the basis of heterotic breeding usually proceeds. The inhibiting effect of inbreeding is well known and is widespread both in plants and in animals. It has been firmly established in the practice of breeding many crops as a method of obtaining combinatory-precious lines with certain positive traits for heterotic breeding.

According to the past studies of alfalfa collection, within 18 mowings in the 6 years of using the herb stand, 40 high-yielding samples were selected with the fodder mass exceeding the standard by $15 \%$ or more. These samples are used as the object of inbreeding.

\section{Conclusion}

By the results of studying the development and use of inbred lines, new results have been obtained for creating combination-valuable inbred lines of alfalfa and sainfoin that are to be used as original components of synthetic varieties:

1. The self-fertility of 250 heterogeneous genotypes that consist of 10 varieties of alfalfa population was studied and 50 elite genotypes were selected

2. Based on the indicators of the level of self-fertility, 313 genotypes of alfalfa were transferred from $J_{2}$ to $\mathrm{J}_{3}$ and 100 elite genotypes with the level of selffertility above $40 \%$ were selected for assessing their general combining ability

3. Genetic diversity with variation from 0.29 to 0.36 units has been established. Absolute homozygosity is not achieved even in highly inbred lines. Genomes of inbred lines have partial similarity both in the spectra of reserve proteins of seeds and in amplifiable DNA fragments of the SSR markers type

4. Out of 1,240 polycross descendants from inbred lines of alfalfa, 75 lines with the level of competitive heterosis of 30 to $50 \%$ have been selected by the level of their general combining ability. They are of interest for breeding synthetic varieties as parent components

5. Using the method of inbred lines' micropropagation from two alfalfa lines (S-21/14 and K-13/07) in the in-vitro conditions, 900 microclonally reproduced mericlones adapted to the conditions of the soil have been obtained

\section{Acknowledgement}

We thanks our Institute for supporting our work.

\section{Author's Contributions}

All authors equally participated in all experiments, coordinated the data

\section{Ethics}

Authors declare no conflicts of interest.

\section{References}

Amanov, M., 2012. Microsatellite marker-based genetic diversity analysis and developing synthetic varieties in alfalfa (Medicago sativa L.). MSc Degree in Biology Thesis, Faculty of Landscape Planning, Horticulture and Agricultural Science (LTJ), Department of Plant Breeding and Biotechnology, Alnarp, Sweden.

Cholastova, T. and D. Knotova, 2012. Markers to assess the genetic diversity in alfalfa (Medicago sativa L.). Int. J. Biol. Food, Vet. Agric. Eng., 6: 146-152. 
Diwan, N., A.A. Bhagwat, G.B. Bauchan and P.B. Cregan, 1997. Simple sequence repeat DNA markers in alfalfa and perennial and annual medicago species. Genome, 40: 887-895. DOI: 10.1139/g97-115

Flajoulot, S., J. Ronfort, P. Baudouin, P. Barre and T. Huguet et al., 2005. Genetic diversity among alfalfa (Medicago sativa) cultivars coming from a breeding program, using SSR markers. Theoretical Applied Genet., 111: 1420-1429. DOI: $10.1007 / \mathrm{s} 00122-005-0074-4$

He, C., Z.L. Xia, T.A. Campbell and G.R. Bauchan, 2009. Development and characterization of SSR markers and their use to assess genetic relationships among alfalfa germplasms. Crop Sci., 49: 2176-2186. DOI: $10.2135 /$ cropsci2007.04.0456

Meirman, G.T., 1991a. About using effect of heterosis in alfalfa breeding. Agric. Biol., 3: 27-38.

Meirman, G.T., 1991b. Breeding inbred lines of alfalfa and their use in the creating a variety population. Bull. Agric. Kazakhstan, 9: 55-59.
Meirman, G.T., 1991c. About the optimal level of selfpollination of the initial forms for heterotic alfalfa breeding. Bulletin Agric. Kazakhstan, 8: 44-49.

Meyrman, G.T., 1986. Soznaniyeiispol'zovaniye v Creating and using inbred lines in alfalfa breeding. Problems of breeding fodder crops and source material: Collection of scientific works in applied botany, genetics and plant breeding. Leningrad: VIR.

Murashige, T. and F. Skoog, 1962. A revised medium for rapid growth and bio assays with Tobacco tissue cultures. Physiol. Plantarum, 15: 473-493. DOI: 10.1111/j.1399-3054.1962.tb08052.x

Portablia, C., F. Casanas, I. Atboquers and L. Bosch, 1982. Phenotypic variation and correlations between morphological and agronomic characters in lucerne (Medicago sativa) Aragon. An. Estac. Exp. Aula Dei, 16: 159-171.

Smolenskaya, S.E., E.V. Kvasova and O.E. Redina, 2008. Testing polymorphism in the varieties and inbred lines of perennial alfalfa. Bulletin VOGiS, 12: 629-635. 